\title{
Invasive pulmonary aspergillosis in neutropenic patients and the influence of hospital renovation
}

\author{
Gabriella Pini, ${ }^{1}$ Elisabetta Faggi, ${ }^{1}$ Rosa Donato, ${ }^{1}$ Cristiana Sacco ${ }^{1}$ and Rosa Fanci ${ }^{2}$ \\ ${ }^{1}$ Department of Public Health, University of Florence, Florence, Italy and ${ }^{2}$ Department of Haematology, University of Florence, Florence, Italy
}

\begin{abstract}
Summary
To evaluate the effects of airborne Aspergillus contamination during and after the renovation work of a Florentine haematology unit, we conducted (November 2003January 2005) a strict programme of environmental fungal surveillance. Air samples were taken from patients' rooms, along the corridors inside the wards, along the corridor between wards and outside the building. The concentration of Aspergillus fumigatus was high along the corridor between the two haematology wards $\left(2.98 \mathrm{CFU} \mathrm{m}{ }^{-3}\right)$, lower in the non-neutropenic patients' rooms and outside the hospital building (1.53 and $1.42 \mathrm{CFU} \mathrm{m}^{-3}$, respectively), very low in the neutropenic patients' rooms $\left(0.09 \mathrm{CFU} \mathrm{m}^{-3}\right)$. During this period, three proven cases (A. fumigatus), two probable ones and two possible cases of invasive pulmonary aspergillosis were documented in 97 patients with acute leukaemia (7\%). The three cases of proven aspergillosis coincided with the period of renovation work and with the period in which we have found the maximum concentration of $A$. fumigatus along the corridor. These data suggest a possible relationship between environmental fungal contamination and the incidence of invasive aspergillosis, and underline the importance of environmental surveillance.
\end{abstract}

Key words: Aspergillus fumigatus, hospital renovation, neutropenic patients, invasive aspergillosis.

\section{Introduction}

Invasive pulmonary aspergillosis (IPA) is a serious infection arising prevalently in immunocompromised patients where there is often a dramatic evolution due to diagnostic and therapeutic difficulties.

The incidence of this disease has been increasing dramatically in the last 30 years due to the increasingly frequent use of immunosuppressive therapy, and is the most common pulmonary mycosis in patients with haematological malignancies. ${ }^{1-3}$

This infection comes about prevalently aerogenically and Aspergillus fumigatus is the main aetiological agent; ${ }^{4}$ nevertheless the mycosis can also be caused by other species such as Aspergillus flavus, Aspergillus niger, Aspergillus terreus and so on.

Correspondence: Gabriella Pini, Dipartimento di Sanità Pubblica, Viale Morgagni, 48, 50134, Florence, Italy.

Tel.: +39055 4598544 . Fax: +39055 4598924

E-mail: gpini@unifi.it

Accepted for publication 3 August 2007
These are environmental fungi isolated mainly in the soil from decomposing vegetation, but also from air and domestic dust. Therefore, it is possible that immunocompromised patients contract the infection in the hospital setting as well.

Fungal contamination inside the hospital is the result of a combination of various factors that are difficult to investigate; however, different authors have established that hospital infections caused by Aspergillus spp. occur with greater frequency when construction work in hospital wards is taking place or has just been completed. $^{5-9}$ This has been associated with the increase of dust in the air, which facilitates the spread of the fungal particles present.

In the period of September 2003-March 2004 major renovation work was carried out in a Florentine haematology unit, thus increasing the risk of fungal, particularly Aspergillus, infections, mainly in patients with acute leukaemia during severe neutropenia related to aggressive chemotherapy.

The aim of this study was to monitor the fungal burden for two purposes: (i) to highlight possible risk 
situations for patients; (ii) to correlate any Aspergillus infections with the fungal burden.

\section{Patients and methods}

\section{Patients}

From November 2003 to January 2005, two haematology wards on the first floor of a Florentine hospital were monitored to make both a qualitative and quantitative evaluation of fungal burden in the air. In this period, 115 haematologic patients were admitted to the wards, 97 of whom $(84 \%)$ were with acute myeloid leukaemia (AML) or acute lymphoblastic leukaemia (ALL).

Patients with acute leukaemia, during the phase of neutropenia, were allocated in one ward where the rooms [multiple-bed rooms without high efficiency particulate air (HEPA) filtration] had restricted access to visitors and other particular behavioural measures: a ban on opening windows and on plants or flowers, measures adopted by the medical and nursing personnel and visitors, such as masks, caps, shoe coverings, sterile gloves and hand-washing.

In the other ward there were non-neutropenic patients with haematological diseases allocated in rooms that had neither restricted access nor particular behavioural measures. All acute leukaemic patients received an aggressive anti-neoplastic regimen for remission-induction, consolidation or relapse/refractory disease and were examined to evaluate the incidence of nosocomial infections. Neutropenia was defined as absolute neutrophil count (ANC) less than 1000 cells $\mu^{-1}>10$ days and severe neutropenia as ANC $<100$ cells $\mu \mathrm{l}^{-1}$. Fever was defined as a single measurement $>38.5^{\circ} \mathrm{C}$ on one occasion or $>38{ }^{\circ} \mathrm{C}$ on two or more occasions within $12 \mathrm{~h}$, not related to underlying disease, chemotherapy or blood infusion.

The characteristics of patients with acute leukaemia during the different phases of intensive chemotherapy, and classification of febrile episodes are shown in Table 1.

Standard antifungal prophylaxis was performed with oral azoles (itraconazole $400 \mathrm{mg} \mathrm{day}^{-1}$ ) and stopped when antifungal therapy was started. Febrile episodes were classified according to EORTC criteria. The diagnosis of proven or probable or possible IPA was based on clinical, radiographic and microbiological data according to established criteria $^{10}$ : (i) clinical factors included neutropenic patients $\left(<500\right.$ neutrophils $\mu l^{-1}$ for $>10$ days); (ii) persistent fever despite broad-spectrum antibacterial therapy; (iii) radiographic evidence included plain radiography or a computed tomography
Table 1 Clinical characteristics of the 97 patients with acute leukaemia

\begin{tabular}{|c|c|c|}
\hline Characteristics & $n$ & Per cent \\
\hline \multicolumn{3}{|l|}{ Age (years) } \\
\hline Mean & 49 & \\
\hline Range & $17-77$ & \\
\hline \multicolumn{3}{|l|}{ Sex } \\
\hline Male & 57 & 59 \\
\hline Female & 40 & 41 \\
\hline \multicolumn{3}{|l|}{ Underlying disease } \\
\hline AML & 84 & 87 \\
\hline ALL & 13 & 13 \\
\hline CVC & 74 & 76 \\
\hline \multicolumn{3}{|c|}{ Initial absolute neutrophil count (ANC) } \\
\hline$<100$ cells $\mu \mathrm{l}^{-1}$ & 37 & 38 \\
\hline $100-500{\text { cells }\left.\mu\right|^{-1}}^{-1}$ & 45 & 46 \\
\hline 500-1000 cells $\mu \mathrm{l}^{-1}$ & 15 & 16 \\
\hline \multicolumn{3}{|l|}{ Days of neutropenia } \\
\hline Mean duration & 15 & \\
\hline Range & $11-40$ & \\
\hline \multicolumn{3}{|l|}{ Status of underlying disease } \\
\hline Remission-induction & 58 & 60 \\
\hline Consolidation & 24 & 25 \\
\hline Relapse/Refractory & 15 & 15 \\
\hline \multicolumn{3}{|l|}{ Prophylaxis } \\
\hline Antibacterial prophylaxis & 89 & 91 \\
\hline Antifungal prophylaxis & 84 & 87 \\
\hline \multicolumn{3}{|c|}{ Classification of febrile episodes } \\
\hline MDI & 45 & 46 \\
\hline CDI & 16 & 18 \\
\hline FUO & 36 & 37 \\
\hline
\end{tabular}

AML, acute myeloid leukaemia; ALL, acute lymphoblastic leukaemia; MDI, microbiologically documented infections with and without bacteraemia; CDI, clinically documented infections; FUO, fever of undetermined origin; CVC, central venous catheter.

scan with the presence of a halo or an air-crescent sign; (iv) microbiologic evidence, when available, was reviewed and included culture and/or microscopic evaluation (cytology or histopathology) or antigen, in bronchoalveolar-lavage fluid (BAL), blood samples, induced sputum, transbronchial biopsy, fine-needle pulmonary aspirations and open lung biopsies.

\section{Methods}

Air samples were taken twice a month between 10:00 and 12:00 A.M. in at least one room of each ward, along the corridors of the wards, along the corridor between the wards and outside the building (270 total air samples). To take the samples we used the Surface Air Systems device (SAS; PBI International, Milan, Italy), which allows direct impact of the air aspirated onto the microbiological culture medium. For this study Sabouraud dextrose agar (Difco, Becton-Dickinson, Sparks, 
MD, USA) mixed with chloramphenicol $0.05 \mathrm{mg} \mathrm{ml}^{-1}$, penicillin $500 \mathrm{U} \mathrm{ml}^{-1}$ and streptomycin $0.5 \mathrm{mg} \mathrm{ml}^{-1}$ contained in 'contact' type plates was used.

Two air samples were taken at every point examined, one plate was incubated to $22{ }^{\circ} \mathrm{C}$ to grow the total mycotic flora and another plate was incubated to $37^{\circ} \mathrm{C}$ to grow the thermophilic mycotic flora (especially A. fumigatus and other Aspergillus species).

After 10 days of incubation, the colonies were counted. Calculating the most probable number of colony forming units (CFU) according to the conversion table provided with the instrument, we reached the concentration for $\mathrm{m}^{3}$ of air $(X)$ with the following formula: $X=\mathrm{CFU} \times 1000 \mathrm{l}^{-1}$ of air drawn.

Identification of the filamentous fungi was made directly from the isolation media, on the basis of both the macroscopic (colour, dimension, aspect) and microscopic (fructification) characteristics of the colony. For the yeasts no species identification was made. Comparison of the quantitative data was made through variance analysis.

\section{Results}

From November 2003 to January 2005 the mean total fungal concentration (culture at $22{ }^{\circ} \mathrm{C}$ ) was significantly higher outside the building (mean $323.55 \mathrm{CFU} \mathrm{m}^{-3}$ ) compared with the restricted access rooms (52.74 $\left.\mathrm{CFU} \mathrm{m}^{-3}, \quad P<0.001\right)$. Moreover, the fungal burden was higher, although not significantly, outside the building (mean $323.55 \mathrm{CFU} \mathrm{m}^{-3}$ ) in comparison with the corridors (mean $220.79 \mathrm{CFU} \mathrm{m}^{-3}$ along the corridors of the wards and $273.58 \mathrm{CFU} \mathrm{m}^{-3}$ along the corridor between the wards) and to the nonrestricted access rooms $\left(194.31 \mathrm{CFU} \mathrm{m}^{-3}\right.$ ) (Table 2).

Cladosporium was the most frequently isolated genus (60.41\% of the total isolated colonies), followed by Penicillium (19.24\%), Alternaria and other Dematiaceae (2.8\%), Aspergillus (2.27\%), Paecilomyces (1.84\%), other hyphomycetes $(13.44 \%)$, yeasts $(1.65 \%)$.

Table 2 Mean fungal concentration $\left(\mathrm{CFU} \mathrm{m}{ }^{-3}\right)$ in haematology wards and outside

\begin{tabular}{lcc}
\hline & $\begin{array}{l}\text { Total fungal } \\
\text { concentration } \\
\left(22^{\circ} \mathrm{C}\right)\end{array}$ & $\begin{array}{l}\text { Total fungal } \\
\text { concentration } \\
\left(37^{\circ} \mathrm{C}\right)\end{array}$ \\
\hline Restricted access rooms & 52.74 & 2.4 \\
Non-restricted access rooms & 194.31 & 7.9 \\
Corridor inside the wards & 220.79 & 11.2 \\
Corridor between the wards & 273.58 & 16.67 \\
Outside & 323.55 & 17.58 \\
\hline
\end{tabular}

In cultures at $37^{\circ} \mathrm{C}$ a lower total fungal concentration compared with that found in cultures at $22^{\circ} \mathrm{C}$ was observed, but even at this temperature the scalarity of the total fungal burden, which was the highest outside and minimum inside the restricted access rooms, was evident (Table 2). The Aspergillus genus was the most isolated $(33.8 \%$ of the total colonies) while other hyphomycetes and yeasts (Dematiaceae, Mucoraceae, Chrysonilia, Chrysosporium, Geotrichum, Penicillium, Schizophyllum, Scopulariopsis, Trichoderma and so on) were isolated occasionally. The Cladosporium genus was never found.

The highest Aspergillus concentration was found along the corridor between the two haematology wards $\left(10.32 \mathrm{CFU} \mathrm{m}^{-3}\right)$, while low concentrations were detected outside the building (3.93 $\mathrm{CFU} \mathrm{m}^{-3}$ ), along the corridors of the wards $\left(3.04 \mathrm{CFU} \mathrm{m}^{-3}\right)$ and in the non-restricted access rooms $\left(3.09 \mathrm{CFU} \mathrm{m}^{-3}\right)$. Aspergillus concentration was $0.53 \mathrm{CFU} \mathrm{m}^{-3}$ in the restricted access rooms (with a highly significant difference compared with the corridor between the wards, $P<0.001$ ) (Table 3).

Aspergillus niger was the most frequently isolated species $(35.08 \%$ of the total Aspergillus colonies), followed by A. fumigatus (33.18\%), A. flavus $(7.85 \%)$, Aspergillus nidulans (3.8\%), A. terreus (2.3\%), Aspergillus clavatus $(0.75 \%)$ and other species not identified (17.04\%).

Aspergillus niger and $A$. fumigatus were isolated especially along the corridor between the wards (3.97 $\mathrm{CFU} \mathrm{m}^{-3}$ and $2.98 \mathrm{CFU} \mathrm{m}^{-3}$, respectively), A. flavus along the corridors inside the wards $\left(1 \mathrm{CFU} \mathrm{m}{ }^{-3}\right)$. In the restricted access rooms, A. niger and A. fumigatus $\left(0.31 \mathrm{CFU} \mathrm{m}^{-3}\right.$ and $0.09 \mathrm{CFU} \mathrm{m}^{-3}$, respectively) were isolated rarely. Aspergillus flavus was never found at this site (Table 3).

A. fumigatus was isolated in particular between January and July 2004 (Table 4).

Table 3 Mean Aspergillus concentration $\left(\mathrm{CFU} \mathrm{m}{ }^{-3}\right)$ in haematology wards and outside (culture at $37^{\circ} \mathrm{C}$ )

\begin{tabular}{|c|c|c|c|c|}
\hline & $\begin{array}{l}\text { Aspergillus } \\
\text { genus }\end{array}$ & $\begin{array}{l}\text { Aspergillus } \\
\text { niger }\end{array}$ & $\begin{array}{l}\text { Aspergillus } \\
\text { fumigatus }\end{array}$ & $\begin{array}{l}\text { Aspergillus } \\
\text { flavus }\end{array}$ \\
\hline $\begin{array}{l}\text { Restricted access } \\
\text { rooms }\end{array}$ & 0.53 & 0.31 & 0.09 & 0 \\
\hline $\begin{array}{l}\text { Non-restricted access } \\
\text { rooms }\end{array}$ & 3.09 & 1.09 & 1.53 & 0.11 \\
\hline $\begin{array}{l}\text { Corridor inside } \\
\text { the wards }\end{array}$ & 3.04 & 0.54 & 0.98 & 1.00 \\
\hline $\begin{array}{l}\text { Corridor between } \\
\text { the wards }\end{array}$ & 10.32 & 3.97 & 2.98 & 0.60 \\
\hline Outside & 3.93 & 1.32 & 1.42 & 0.10 \\
\hline
\end{tabular}




\begin{tabular}{lllllll}
\hline $\begin{array}{l}\text { Monitoring } \\
\text { date }\end{array}$ & Season & $\begin{array}{l}\text { Restricted } \\
\text { access } \\
\text { rooms }\end{array}$ & $\begin{array}{l}\text { Non-restricted } \\
\text { access } \\
\text { rooms }\end{array}$ & $\begin{array}{l}\text { Corridor } \\
\text { inside } \\
\text { wards }\end{array}$ & $\begin{array}{l}\text { Corridor } \\
\text { between } \\
\text { the wards }\end{array}$ & Outside \\
\hline $12 / 11 / 03^{*}$ & Autumn 03 & 0 & 0 & 0 & 0 & 0 \\
$27 / 11 / 03^{*}$ & & 0 & 0 & 0 & 4.17 & 0 \\
$11 / 12 / 03^{*}$ & & 0 & 0 & 0 & 0 & 0 \\
$14 / 01 / 04^{*}$ & Winter 03-04 & 0 & 0 & 0 & 8.33 & 0 \\
$28 / 01 / 04^{*}$ & & 0 & 4.88 & 0 & 16.67 & 0 \\
$11 / 02 / 04^{*}$ & & 0 & 0 & 0 & 0 & 3.38 \\
$25 / 02 / 04^{*}$ & & 0 & 0 & 0 & 0 & 16.18 \\
$09 / 03 / 04^{*}$ & & 0 & 0 & 0 & 0 & 0 \\
$23 / 03 / 04^{*}$ & Spring 04 & 0 & 0 & 0 & 8.33 & 0 \\
$06 / 04 / 04$ & & 0 & 0 & 4.00 & 0 & 0 \\
$05 / 05 / 04$ & & 0 & 12.58 & 0 & 4.17 & 0 \\
$19 / 05 / 04$ & & 1.99 & 0 & 4.17 & 8.33 & 0 \\
$09 / 06 / 04$ & & 0 & 0 & 4.17 & 0 & 0 \\
$30 / 06 / 04$ & Summer 04 & 0 & 3.57 & 0 & 0 & 6.65 \\
$07 / 07 / 04$ & & 0 & 0 & 8.33 & 0 & 3.58 \\
$10 / 09 / 04$ & & 0 & 0 & 0 & 0 & 0 \\
$22 / 09 / 04$ & Autumn 04 & 0 & 3.57 & 0 & 0 & 0 \\
$05 / 10 / 04$ & & 0 & 0 & 0 & 0 & 0 \\
$04 / 11 / 04$ & & 0 & 0 & 0 & 0 & 0 \\
$01 / 12 / 04$ & & 0 & 7.53 & 0 & 12.5 & 0 \\
$18 / 01 / 05$ & Winter 04-05 & 0 & 0 & 0 & 0 & 0 \\
\hline
\end{tabular}

Table 4 Aspergillus fumigatus concentration $\left(\mathrm{CFU} \mathrm{m}{ }^{-3}\right)$ in the haematology wards and outside the hospital during the monitored period

*In this period renovation work was in progress.

This species was found mainly along the corridor between the wards where it was isolated almost exclusively in the period coinciding with or immediately after the renovation work taking place between September 2003 and March 2004. There were positive samples along the corridor inside the wards only in spring and summer 2004. In the restricted access rooms, A. fumigatus was isolated only one time (spring 2004). In the non-restricted access rooms it was found occasionally in all seasons. Outside this species was isolated only four times (in winter and summer 2004) (Table 4).

From November 2003 to January 2005, 15 atypical lung infiltrates were observed in chest tomography in patients with acute leukaemia. They were classified as proven/suspected invasive fungal infections in seven cases $(7 \%)$, as shown in Table 5. All patients were febrile and with severe neutropenia.

The three cases of proven aspergillosis took place in the period of January-February 2004; the other cases between March and December 2004 (Table 5).

\section{Discussion}

The data obtained during this study show that the total fungal concentration (cultures at $22^{\circ}$ and $37^{\circ} \mathrm{C}$ ) tends to increase from closed to open areas in the haematology wards, reaching a maximum outside the building. The low number of propagules found in the restricted
Table 5 Invasive pulmonary aspergillosis (IPA) cases during the monitored period

\begin{tabular}{lllll}
\hline Patient & Leukaemia & Diagnosis & Date diagnosis & Aetiology \\
\hline 1 & ALL & $\begin{array}{l}\text { Proven } \\
\text { IPA }\end{array}$ & January 2004 & $\begin{array}{c}\text { Aspergillus } \\
\text { fumigatus }\end{array}$ \\
2 & AML & $\begin{array}{l}\text { Proven } \\
\text { IPA }\end{array}$ & January 2004 & A. fumigatus \\
3 & AML & $\begin{array}{l}\text { Proven } \\
\text { IPA }\end{array}$ & February 2004 & A. fumigatus \\
4 & AML & $\begin{array}{l}\text { Possible } \\
\text { IPA }\end{array}$ & March 2004 & \\
5 & AML & $\begin{array}{l}\text { Possible } \\
\text { IPA }\end{array}$ & April 2004 & \\
6 & AML & $\begin{array}{l}\text { Probable } \\
\text { IPA }\end{array}$ & September 2004 & Aspergillus spp. \\
7 & AML & Probable & December 2004 & Aspergillus spp. \\
& & IPA & & \\
\hline
\end{tabular}

ALL, acute lymphoblastic leukaemia; AML, acute myeloid leukaemia.

access rooms of the ward may be the result of the level of environmental isolation (entrance limited to a minimum number of people, a ban on opening windows and so on).

The use of a double incubation temperature $\left(22^{\circ}\right.$ and $37^{\circ} \mathrm{C}$ ) of the specimens allowed us to evaluate both the total fungal concentration (to monitor the degree of total fungal contamination) and the thermophilic 
mycotic flora concentration (to better highlight thermophile species such as A. fumigatus and other Aspergillus species, which in a $22{ }^{\circ} \mathrm{C}$ culture could be inhibited by non-thermophile species, as Cladosporium and Penicillium, that are extremely abundant in the air or have a quicker growth rate).

The Aspergillus distribution in the different environments monitored does not seem to reflect what has been observed for the total fungal burden. In fact, the Aspergillus concentration within the building is, excluding the restricted access rooms, similar or greater than that observed outside.

The greatest Aspergillus concentration was found along the corridor between wards which was directly connected to the construction zone. So the dust that raised during the renovation, the humidity and temperature of a heated environment (the work took place in autumn-winter) may have contributed to the proliferation of these thermophile species.

In the restricted access rooms the total mycotic burden was always low and the Aspergillus burden was even lower. Thus we might think that the level of environmental isolation (entrance limited to a minimum number of people, a ban on opening windows and so on) was valid.

Aspergillus niger was the most frequently isolated species, but there were no cases directly ascribable to this species; the three case of certain aspergillosis were all attributed to A. fumigatus.

The correlation between the concentration of A. fumigatus in the air and cases of invasive aspergillosis has been recognised by various authors. ${ }^{8,11,12}$ In particular, Arnow et al. [11] observed that the increase in the mean concentration of A. fumigatus and A. flavus was accompanied by a progressive increase in the incidence of aspergillosis. In fact, they noticed that during a preepidemic period the concentration of $A$. fumigatus and A. flavus had been less than 0.01 and $0.2 \mathrm{CFU} \mathrm{m}^{-3}$, respectively while in an epidemic period the concentration rose to 1.1 and $2.2 \mathrm{CFU} \mathrm{m}{ }^{-3}$, respectively.

In our research, we found a high concentration of $A$. fumigatus along the corridor between wards, especially in the period coinciding with or immediately after the renovation work. On this site the mean concentration of A. fumigatus in the entire period observed (November 2003-January 2005) was $2.98 \mathrm{CFU} \mathrm{m}^{-3}$ but, if we consider only the period November 2003-March 2004 (coinciding with the renovation work) and the two following months (April-May 2004), this reaches 4.17 $\mathrm{CFU} \mathrm{m}^{-3}$. Aspergillus fumigatus may have passed from the corridor between wards to places strictly contiguous such as the corridor inside the wards (mean concentration $0.98 \mathrm{CFU} \mathrm{m}^{-3}$ ) and the rooms of nonneutropenic patients without restricted access (mean concentration of $1.53 \mathrm{CFU} \mathrm{m}^{-3}$ ). Before the neutropenia phase related to chemotherapy, patients stay in rooms without restricted access and use the corridors inside and between the wards and thus may inhale these micro-organisms in these locations. Indeed, in our experience, the cases of proven aspergillosis coincide with the period of renovation work and with the period in which we have found the maximum concentration of A. fumigatus in the corridor.

The possibility of a correlation between Aspergillus concentration and cases of aspergillosis also seems to be confirmed by our earlier published study. ${ }^{13}$ Indeed, in the years 1999-2000, during research conducted in the same haematology wards, we found extremely low concentrations of A. fumigatus $\left(0.09 \mathrm{CFU} \mathrm{m}^{-3}\right.$ in the rooms, $0.21 \mathrm{CFU} \mathrm{m}^{-3}$ along the corridors) and no case of invasive aspergillosis was documented. Moreover, in a previous clinical surveillance (unpublished data), performed in the period 2001-2002 on the same patient population (100 acute leukaemic patients) and in the absence of building construction work, we documented only two possible fungal pneumonias (2\%).

In conclusion, this study suggests a possible relationship between environmental fungal contamination in haematologic patients and the incidence of invasive aspergillosis, and also underlines the importance of environmental surveillance.

\section{References}

1 Martino R, Subira M. Invasive fungal infections in hematology: new trends. Ann Hematol 2002; 81: 233-43.

2 Marr KA, Carter RA, Crippa F, Wald A, Corey L. Epidemiology and outcome of mould infections in hematopoietic stem cell transplant recipients. Clin Infect Dis 2002; 34: 909-17.

3 Pagano L, Caira M, Candoni A et al. The epidemiology of fungal infections in patients with hematologic malignancies: the SEIFEM-2004 study. Haematologica 2006; 91: 1068-75.

4 Warris A, Verweij PE. Clinical implications of environmental sources for Aspergillus. Med Mycol 2005; 43(Suppl 1): S59-65.

5 Arnow PM, Andersen RL, Mainous PD, Smith EJ. Pulmonary aspergillosis during hospital renovation. Am Rev Respir Dis 1978; 118: 49-53.

6 Oren I, Haddad N, Finkelstein R, Rowe JM. Invasive pulmonary aspergillosis in neutropenic patients during hospital construction: before and after chemoprophylaxis and institution of HEPA filters. Am J Hematol 2001; 66: 257-62. 
7 Nolard-Tintigner N, Snoeck R, Leleux A, Beguin H, Moonens F, Meunier-Carpentier F. Mise en evidence d'Aspergillus fumigatus lors de travaux de construction et de rénovation en milieu hospitalier. Bull Soc Fr Mycol Méd 1985; 14: 93-98.

8 Nolard N. Les liens entre les risques d'aspergillose et la contamination de l'environnement. Path Biol 1994; 42: 706-10.

9 Barnes RA, Rogers TR. Control of an outbreak of nosocomial aspergillosis by laminar air-flow isolation. J Hosp Infect 1989; 14: 89-94.

10 Ascioglu S, Rex JH, de Pauw B et al. Defining opportunistic invasive fungal infections in immunocompromised patients with cancer and hematopoietic stem cell trans- plants: an international consensus. Clin Infect Dis 2002; 34: $7-14$.

11 Arnow PM, Sadigh M, Costas C, Weil D, Chudy R. Endemic and epidemic aspergillosis associated with in-hospital replication of Aspergillus organisms. J Infect Dis 1991; 164: 998-1002.

12 Alberti C, Bouakline A, Ribaud P et al. Relationship between environmental fungal contamination and the incidence of invasive aspergillosis in haematology patients. J Hosp Infect 2001; 48: 198-206.

13 Pini G, Donato R, Faggi E, Fanci R. Two years of a fungal aerobiocontamination survey in a Florentine haematology ward. Eur J Epidemiol 2004; 19: 693-8. 